\title{
SISTEMA ÚNICO DE SAÚDE E A REFORMA PSIQUIÁTRICA: DESAFIOS E PERSPECTIVAS
}

\author{
Unified Health System and Psychiatric Reform: challenges and perspectives
}

Sistema de Salud y Reforma Psiquiátrica: Retos y Perspectivas

Tatiana Benevides Magalhães Braga Marciana GonÇalves Farinha

\begin{abstract}
Resumo: Este artigo apresenta as transformações no processo de constituição da saúde mental e suas aproximações e distanciamentos com a Saúde Coletiva no Brasil, em especial entre os movimentos das reformas psiquiátrica e sanitária. Analisando os paradoxos, lacunas, impasses, desafios e perspectivas da construção da autonomia do sujeito em situação de sofrimento grave, discute como as dificuldades encontradas na desinstitucionalização psiquiátrica entrelaçamse em campos de consonância e conflito. Nesse contexto, torna-se fundamental a desconstrução e desnaturalização das perspectivas epistemológicas dificultadoras da autonomia do sujeito, cabendo resgatar importantes influências do pensamento fenomenológico que percorreram o processo de reforma psiquiátrica e continuam a se fazer ouvir na consideração da totalidade da existência dos sujeitos e no questionamento do determinismo sobre a subjetividade. A articulação de propostas de problematização e reinvenção das relações humanas nos dispositivos substitutivos permitem a crítica a uma miscigenação das concepções manicomiais nos próprios serviços de saúde mental. Palavras-chave: Reforma Psiquiátrica, SUS, sofrimento existencial
\end{abstract}

\begin{abstract}
This article presents the transformations in the mental health constitution process and their approximations and distancing with the collective health in Brazil, specially between the Psychiatric and sanitary reform movements. Analyzing the paradoxes, gaps, impasses, challenges and perspectives of the subject autonomy construction in a grave suffering situation, discuss how the difficulties found in the psychiatric deinstitutionalization intertwine themselves on consonance and conflict fields. In this context, it becomes fundamental the deconstruction and denaturalization of the epistemological perspective that difficult the subject's autonomy, fitting to rescue important influences of the phenomenological thought that went through the psychiatric reform process and are still making themselves to be listened in the consideration of the subjects existence totality and in the questioning of the determinism over the subjectivity. The proposals articulation of the human relations questioning and reinvention in the substitutive devices allows the critic to the manicomials conceptions miscegenation in the same mental health services. Keywords: Mental health, Psychiatric reform, Single Health System, deinstitutionalization, Existential suffering
\end{abstract}

Resumen: Este artículo presenta los cambios en la constitución del proceso de salud mental y sus similitudes y diferencias con la salud pública en Brasil, especialmente entre los movimientos de la reforma psiquiátrica y la reforma sanitaria. El análisis de las paradojas, las lagunas, callejones sin salida, retos y perspectivas de la construcción de la autonomía de la persona en situación de peligro grave, discute cómo las dificultades encontradas en entrelazar desinstitucionalización psiquiátrica en campos de las líneas y los conflictos. En este contexto, es esencial para deconstruir y desnaturalizar causan dificultades perspectivas epistemológicas de la autonomía del sujeto, dejando de rescate influencias importantes del pensamiento fenomenológico que pasaron por el proceso de reforma psiquiátrica y continuar con el conocimiento en consideración de la totalidad de la existencia de los sujetos y cuestión del determinismo sobre la subjetividad. El interrogatorio conjunto de propuestas y reinvención de las relaciones humanas en los dispositivos sustitutivos permitió la crítica a un mestizaje de los conceptos de los manicomios en los propios servicios de salud mental. Palabras-clave: Reforma Psiquiátrica, SUS, desinstitucionalización, sufrimiento existencial

\section{A herança histórica: loucura, purificação e exclusão social}

O estudo problematiza impasses vividos pela reforma psiquiátrica brasileira a partir de um percurso que realça: 1) a construção histórica de posicionamentos epistemológicos diversos para o chamado terceiro momento da reforma psiquiátrica, que comporta a reformulação das concepções em torno do sofrimento existencial grave; 2) a influência da perspectiva fenomenológica, relevante e ainda pouco conhecida no Brasil e 3) o cenário político brasileiro, tanto em termos de investimento estatal quanto de aproximações e distanciamentos entre saúde mental e saúde coletiva - em especial entre reforma psiquiátrica e sanitária. Busca-se assim compreender o pano de fundo da permanência de práticas manicomiais na rede substitutiva.

Inicialmente cabe resgatar a construção histórica do olhar da psiquiatria clássica, já que historicamente a loucura não foi sempre compreendida a partir da noção de doença mental. Na Antiguidade, associava-se com o divino: os oráculos, o destino das tragédias gregas, os demônios expulsos na Bíblia (Serrano, 1986), ou a aspectos orgânicos ligados aos hábitos e à harmonia com o cosmos, como em Hipócrates, Platão e Galeno (Pessotti, 1994; Costa-Rosa, 2000). Na Idade Média, a loucura passa a 
ser assimilada nas comunidades ou vinculada ao sobrenatural no chamado de Deus ou na presença do demônio, para a qual eram endereçadas purificações rituais: exorcismos, peregrinações, orações e penitências (Foucault, 2014).

No fim da Idade Média, o ideal de homem racional e autocontrolado, ligado à organização monetária, cultural e produtiva do capitalismo nascente, operou a exclusão de aspectos desviantes: os afetos, a morte, a loucura... Inicia-se então a exclusão direta: os transportados nas naus dos loucos não conseguiam asilo permanente nos burgos e o louco torna-se itinerante, sem pertença fixa (Foucault, 2014). Desde a alta Idade Média, os leprosos eram internados nos leprosários em isolamento permanente e sem tratamento. No século XV, junto à errância dos loucos, a prática de evitar contágio extingue a lepra da Europa, tornando a exclusão social metodologia de saúde: a separação entre doentes e sãos na erradicação da lepra gerou bases para uma cisão dualista entre normal e patológico (Foucault, 2014). Contida a lepra, os leprosários assumem entre os séculos XIV e XVII a internação de doentes venéreos e, posteriormente, degenerados e desviantes de toda espécie - inválidos e idosos na miséria, prostitutas, pobres, vagabundos, presidiários e 'cabeças alienadas' (Foucault, 2014, p. 6), numa cultura de trabalho forçado e disciplinamento pelo castigo e pela ordem. Germina-se um olhar sobre a loucura como objeto de correção, análise e manipulação, que resultará, no século XIX, em seu diagnóstico e tratamento. A loucura figura então como o negativo do trabalho e da razão - antítese do ideal humano da cultura burguesa em constituição.

Ao fim da Idade Moderna, a Revolução Francesa destitui os sistemas de internação, considerados símbolo do antigo poder autoritário. Porém os mantém para o louco, avaliado pela razão iluminista como perigoso se liberto (Foucault, 2014). No ideário racionalista, Pinel, ligado ao grupo revolucionário, reorganiza os hospitais franceses e toma o louco como objeto tanto de disciplina quanto trato médico. Tal ato inaugura a psiquiatria clássica, que nasce como paradoxal reforma: livre de correntes e punições, o louco perdura ainda mais assentado ao espaço fechado (Foucault, 2014; Basaglia, 2001) - sua patologia é tida como inerente, oposta ao normal, seu tratamento é um ajuste a modelos sociais de conduta.

\section{A psiquiatria clássica e a biologização epistemológica da loucura}

No binômio normal-patológico, a psiquiatria estipula elos entre condutas do louco e funcionamento orgânico. À guisa da medicina orgânica, a medicina mental a princípio alocou a essência da doença em grupos de sintomas, criando uma sintomatologia e uma nosografia (Foucault, 2000). Na sintomatologia, referem-se nexos entre doença e expressão mórbida: a alucinação torna-se sintoma de uma estrutura orgânica delirante; a confusão mental, sintoma de uma estrutura demente. Na nosografia, analisa-se a evolução da doença: variantes, caráter agudo ou crônico, alternâncias de sintomas. Instituem-se, assim, ligações entre sintoma e neurohipótese, visando garantir à loucura o status de doença e à psiquiatria o status de medicina em sua lógica clássica: classificação do sintoma, indicação de relações de causa e efeito entre sintoma e agente causador e, enfim, a delimitação da doença, com agentes definidos, sintomas relacionados, previsão de evolução e definição de tratamento.

Tome-se como exemplo a esquizofrenia. Em 1860, Morel tipifica na demência precoce um grupo de sintomas que inclui delírios, alucinações, pensamento bizarro, tem início na juventude e evolui para a perda de funções cognitivas. Sustenta a neurohipótese da degeneração cerebral. Hecker, em 1871, agrupa na hebefrenia (do grego, alma infantil) sintomas semelhantes, mas não exige evolução para a demência, destaca a puerilidade e hipotetiza falhas no desenvolvimento cerebral. Em 1874, Kahlbaum agrupa tais sintomas como catatonia destaca embotamento afetivo e autismo e associa parte deles à sífilis.

Com Kraepelin, na virada do século, as neurohipóteses migram da anatomia cerebral para a fisiologia: se de início considera a demência precoce processo degenerativo, posteriormente toma-o como metabólico (Elkis, 2000). Kraepelin reagrupa os diagnósticos anteriores em subtipos da demência precoce (hebefrênica, catatônica, paranóide e mais tarde outros). Separa subgrupos pela perda ou aumento da atividade cerebral e os associa a 48 sintomas. Embora reconhecesse cura em 25\% dos casos e propusesse diagnóstico longitudinal, observando a evolução dos sintomas no tempo (Foucault, 2000, Elkis, 2000), reafirma seu caráter orgânico. No início do século XX e sob influência de Freud, Bleuler passa a considerar aspectos psicológicos no diagnóstico do conjunto patológico que ele renomeia esquizofrenia. A junção das palavras gregas esquizo (dividido), e frenos (alma), aponta para a ênfase bleuriana na cisão entre pensamento, emoção e comportamento nos sujeitos afetados (Elkis, 2000). Haveria sintomas orgânicos e psíquicos, todavia considerar aspectos psíquicos não significou alterar pressupostos: os sintomas fundamentais seriam orgânicos, pois refletiriam uma alteração cerebral, enquanto os sintomas psíquicos são denominados "acessórios", meras reações à condição adoecida e expressão secundária dos sintomas primários. Além disso, Bleuler considera a possibilidade de ocorrer agravamento, estacionamento ou regressão dos sintomas, porém nunca sua remissão completa. Perdura a tentativa de articular a conduta do louco e substratos orgânicos correspondentes, ainda que tais nexos não fossem precisamente demonstráveis. Nesse paradigma, a loucura é abarcada pela noção de "doença mental”, que pressupõe um grupo de sintomas de base orgânica e causas identificáveis por exames e acompanhamento clínico (Foucault, 2000).

\section{Epistemologias ampliadas: fenomenologia e saúde mental}

No fim do século XIX, já brotavam abordagens psicopatológicas não biologizantes, que bus- 
cavam considerar o sujeito para além do âmbito estritamente orgânico. Breuer e Freud (1895/1990) propuseram a relação entre sintomas neuróticos e experiências vividas e representadas no psiquismo. Embora haja contribuições da psicologia analítica, de Reich, da psicanálise e de outros autores, o presente texto discutirá a influência da fenomenologia no questionamento do olhar da psiquiatria tradicional sobre a loucura, menos conhecida no Brasil. Pouco depois dos primeiros escritos de Husserl que fundam a fenomenologia, ela fecunda a psicopatologia. Em Psicopatologia Geral (1913/2003), Jaspers desconstrói várias acepções sobre a loucura cimentadas ao longo de sua história de exclusão. Critica noções forjadas na Idade Moderna que aproximam loucura e animalidade, reputando a loucura à desrazão; toma o delírio como alteração do juízo e afirma que apenas aqueles os de julgar seriam capazes de delirar, situando a loucura como eminentemente humana; critica ainda a noção estrutural de personalidade, afirmando que o homem não pode ser concebido como coisa com propriedades, mas como "ser em seu mundo" (Jaspers, 1913/2003, p. 21), em desenvolvimento e diferenciação de si; critica o método quantitativo de classificação dos sintomas como único modo de saber sobre a doença, advogando pelo método fenomenológico e pela escuta dos relatos de pacientes, entre outros temas.

Entre 1930 e 1950, Binswanger (2009, 2013) cria a Daseinsanalyse, método conjuntamente compreensivo e terapêutico dos fenômenos psicóticos. Influenciado por Husserl e Heidegger, propõe suspender conceitos prévios da psicopatologia e rejeita pensar o sofrimento como cisão entre fatores internos e externos, pois reforçaria a cisão entre sujeito e objeto que a noção husserliana de intencionalidade procura ultrapassar. Para Binswanger, (2013), o homem é existência em sua história de vida e o fenômeno psicopatológico não é isolado, mas processual: existir no mundo articula o sentido dos estados psicopatológicos, enquanto alterações nas condições ontológicas da existência - experiência temporal, espacialidade, corporeidade, etc. (Tatossian \& Moreira, 2012). Numa fenomenologia genética que toma a existência como presença no mundo, Binswanger descreve os pacientes propondo alguns modos de experiência, como mania, melancolia (Tatossian \& Moreira, 2012), extravagância, excentricidade e amaneiramento (Binswnager, 2009), ligando-os às dificuldades do fluir da experiência.

O pressuposto somático diretamente ligado à manifestação sintomatológica havia feito persistir, no século XIX e na primeira metade do século XX, a primazia da ótica epistemológica de tratamento e intervenção no corpo, excluindo esferas relacionais, condições materiais de vida ou lugares sociais dos diagnosticados. A consolidação de um olhar negativo sobre a doença mental (o doente mental como deficitário em relação ao indivíduo são que, portanto, perde algo de sua própria humanidade), forjou bases das relações de violência concreta e simbólica instituídas não apenas no espaço asilar, mas no convívio entre o então doente mental e os profissionais, familiares e atores sociais.
A acepção de uma racionalidade deficitária de cunho orgânico permitiu, ainda, o controle moral, a deslegitimação e a negação dos discursos daqueles classificados como doentes mentais (Amarante, 2016; Foucault, 2000). Goffman (2001) descreve diversos mecanismos pelos quais o interno é levado a assumir a identidade social construída institucionalmente no espaço do hospital psiquiátrico: a perda de contato com o mundo externo, a destituição da identidade civil e assunção ritual da identidade institucional, a perda do estojo de identidade, a perturbação da economia, a consideração de quaisquer reações fora do padrão esperado como sinais indeléveis que atestam a condição de doente do sujeito. Também Basaglia (2010) aponta relações de dominação baseadas na violência como principal característica das instituições asilares tradicionais. No cenário do hospício, a organização dos espaços-tempos é promotora de identidades cronificadas (Lancetti, 2011). O modelo forjado pela psiquiatria no fim do século XVIII, dominante até a década de 1960 e ainda presente no século XXI, carrega a herança de um profundo processo de exclusão e assujeitamento dos indivíduos considerados desviantes, coopera na degradação e segregação dos diagnosticados, levando-os ao aprisionamento social no lugar de estigmatizado e, portanto, cronificado, da doença mental.

\section{Abordagens ampliadas e o início da reforma psiquiátrica}

O advento de críticas teóricas ao binômio sintoma-base orgânica não operou a mudança imediata da práxis dominante. Foi sobretudo após a Segunda Guerra Mundial que o cenário de tratamento e compreensão do sofrimento humano transformou-se significativamente (Amarante, 2016, Pessoti, 2006). Várias condições socioeconômicas e históricas entrelaçaram-se no estabelecimento de novas experiências para lidar com a loucura: o contexto de guerra tornou cara a manutenção da estrutura asilar e aumentou a demanda psiquiátrica e por reabilitação em geral, o desmonte dos campos de concentração levou à desconfiança quanto às instituições totais, o crescimento dos movimentos populares e das mudanças na estrutura política aumentou a reivindicação por direitos e à formação do Estado de Bem-Estar Social europeu.

É no contexto da Segunda Guerra Mundial que surge a experiência socioterápica, primeiro ensaio de reestruturação asilar, pelas comunidades terapêuticas desenvolvidas por Maxwell Jones na Escócia (Jones, 1972), a partir de $1938^{1}$. Com a escassez de recursos e a crescente demanda por atendimento, Jones passou a propor que os próprios pacientes participassem da organização institucional, baseada no acordo coletivo e em assembleias, e ainda na

\footnotetext{
1 Também na primeira metade do século XX surgiram nos Estados Unidos as experiências de Comunidades Terapêuticas de cunho religioso. Seus pormenores não serão discutidos nesse breve histórico apresentado sobre a reforma psiquiátrica no plano internacional, porém sua influência será reconsiderada adiante, quando for abordado o problema das comunidades terapêuticas no panorama da reforma psiquiátrica brasileira, considerando suas tensões frente à discussão político-epistemológica em torno da ressocialização atinente aos dispositivos governamentais e de saúde.
} 
forma grupal de diversas atividades terapêuticas, enfatizando a troca de experiências. As comunidades terapêuticas adotaram como princípios: uso da organização institucional como método terapêutico, democratização das relações institucionais, apreciação do potencial terapêutico de todos os vínculos desenvolvidos, acepção de que a tolerância e o acolhimento de experiências disruptivas compõem o ambiente terapêutico, ênfase na qualidade comunicacional, na realização de atividades e experiências produtoras de sentido e na promoção de retorno rápido ao meio aberto.

Ainda no âmbito asilar, a análise institucional buscou transformar as instituições hospitalares aliando teoria e prática pela reflexão sobre os procedimentos comuns no interior dos espaços institucionais de internamento das pessoas em sofrimento existencial, propondo intervenções não centradas no poder autoritário do saber médico (Passos, 2009). As experiências de psicoterapia institucional nas propostas francesas de Jean Oury e François Tosquelles propunham uma mudança efetiva de perspectiva no tratamento. Todavia, mormente se limitaram a sanear os hospitais com maior limpeza e organização, ampliar a oferta de serviços externos de assistência aos enfermos, de modo amiúde ainda autoritário, abrir visitas nas instituições, e diminuir o tempo de internação (Passos, 2009).

Tais experiências se limitaram a reestruturar o âmbito asilar, visando considerar a perspectiva dos atendidos e muitas vezes integrá-los à gestão institucional cotidiana. Seu aspecto mais significativo residiu na consideração dos sujeitos para além do lugar da doença, que foi elemento chave para a ampla melhora dos pacientes, bem como para impedir processos de cronificação frequentes nos manicômios tradicionais. As propostas socioterápicas, posteriormente expandidas para outros locais do mundo, demonstraram na prática a presença de uma profecia auto realizadora na racionalidade psiquiátrica: ao tomar como prognóstico altamente provável a cronificação considerada exclusivamente orgânica e destituir o interno de qualquer responsabilidade, escolha sobre si ou liberdade sobre a construção de sua subjetividade, o próprio discurso psiquiátrico produziria cronificação. Refutando tal lógica em favor da autonomia e do acordo coletivo e assim obtendo melhores resultados, a experiência socioterápica permitiu construir uma base epistemológica e prática para a Reforma Psiquiátrica.

A despeito de seus resultados, a reestruturação asilar não alcançava o momento posterior à internação, gerando amiúde uma situação na qual os atendidos permaneciam em boas condições enquanto estivessem internados, porém voltavam a entrar em crise no contato com as dificuldades vividas anteriormente à internação. Isso evidenciou a necessidade de atenção territorial, gerando experiências como a psiquiatria de setor e a psiquiatria preventivo-comunitária, que buscaram a profilaxia do sofrimento psíquico, projeto que "não visa simplesmente à terapêutica e à prevenção das doenças mentais, mas constrói um novo objeto: a saúde mental” (Amarante, 2016, p. 89). A ótica profilática, privilegiando ainda a epistemologia de um sofrimento exclusivamente orgânico, muitas vezes serviu à patologização das experiências humanas. Com a classificação psiquiátrica, indivíduos com relativa integração a seu contexto passaram a vivenciar a deslegitimação social. Com sua experiência reduzida ao sintoma, ampliaram estatísticas de internação psiquiátrica ao invés de preveni-las e reduzi-las. Revela-se a potência estigmatizante e redutora da lógica organicista criando profecias autorrealizadoras no meio social.

Enquanto as propostas de reforma asilar e psiquiatria profilática voltaram-se à reformulação do atendimento, abordagens mais avançadas de reforma partiram do questionamento da própria epistemologia psiquiátrica (Puchivailo, Silva, \& Holanda, 2013). Ao desenvolver alternativas à lógica biologizante sobre a loucura, tais abordagens retomam o caráter historicamente paradoxal dessa lógica, revelando-a como ideologia social que mescla tratamento e exclusão (Basaglia, 2001, 2010). Propostas como a esquizoanálise (Deleuze \& Guatarri, 2015), a antipsiquiatria (Laing, 1991; Cooper, 2013) e a psiquiatria democrática (Basaglia, 2001, 2010) articuloam a racionalidade psiquiátrica ao próprio capitalismo, afirmando a necessidade de um olhar sobre a loucura que não se restrinja ao âmbito biológico e individual, mas compreenda a experiência humana na totalidade de suas interfaces de constituição, trazendo à baila dimensões de ordem psíquica, social e política (Foucault, 2006, Serrano, 1986).

Para a antipsiquiatria (Laing, 1991), a crise seria a emergência de vivências caladas pelo sujeito frente à necessidade de adaptação social. A psiquiatria, procurando controlar sintomas, incidiria no mesmo processo gerador da crise, cronificando-o. Para a esquizoanálise (Deleuze \& Guattari, 2015), as vivências de crise e sofrimento estão agudamente ligadas à restrição de experiências e laços sociais potencializadores no contexto do capitalismo. Já para Basaglia (2010), a prática psiquiátrica funcionou como dispositivo de opressão das classes pobres, desconsiderando a gênese multidimensionada do sofrimento e sua articulação com o contexto social mais amplo.

Na Europa, tais experiências levaram a reformulações profundas que deslocaram o debate do âmbito meramente técnico para o campo político, envolvendo trabalhadores, movimentos sociais e sociedade em geral. Em nossa análise, abarcamos a perspectiva de Foucault (2006), para quem a antipsiquiatria e a psiquiatria democrática consistiam não apenas em tentativas de melhorar os serviços de saúde, mas em um autêntico rompimento com a lógica disciplinar da psiquiatria clássica. Considerando ainda que a Psiquiatria Democrática consistiu não apenas na experiência de um serviço, mas numa ampla alteração da política pública italiana em saúde mental, muito influente na reforma psiquiátrica brasileira, e que seu pensamento teve relevante inspiração fenomenológica, optou-se por destacá-la. Foi a partir da problematização da articulação entre prática psiquiátrica e relações de opressão que o caráter de reinserção social foi instituído na reforma psiquiátrica italiana, passando a constar na lei 180 (Basaglia, 2010). 


\section{Assistência em saúde mental no Brasil: panorama político e diretrizes epistemológicas}

No Brasil, a reforma psiquiátrica inicia-se no final da década de 1970, num cenário em que diversos movimentos sociais se entrecruzavam reivindicando o fim da Ditadura Militar (1964-1985), abertura política e ampliação de direitos. Para entender o atendimento público em saúde mental anterior à reforma, importa destacar que isso consiste num hiato de trinta anos em relação à Europa: enquanto a reforma avança e estatiza-se na Europa nos anos 1970, amplia-se o parque manicomial brasileiro na Ditadura Militar. Em 1974, o governo assinou o Plano de Pronta Ação, convênio com hospitais psiquiátricos privados que repassava-lhes recursos públicos destinados à assistência psiquiátrica, chegando a absorver mais de $90 \%$ das verbas voltadas à saúde mental no país (Waidman \& Elsen, 2006; Vecchia \& Martins, 2009). Com ele, o número de leitos psiquiátricos cresceu exponencialmente: em 1961, havia 140 hospitais psiquiátricos, sendo 86 privados; em 1971, esse número subiu para 340, com 277 hospitais privados; em 1981, só na rede privada eram 425 hospitais (Messas, 2008, p. 93). Nessa expansão, não foi garantida a qualidade do serviço prestado, e sobejaram violações aos direitos humanos: o holoucausto de Barbacena (Arbex, 2013), a internação de foragidos políticos (Arbex, 2013) e a escravização de pessoas em condição de deficiência mental do estado de Goiás (Meirelles, 2016) ilustram esse panorama.

Na década de 1980 a junção de diversos fatores constrói um panorama histórico propício à Reforma Psiquiátrica: na esfera política, a redemocratização anima a discussão sobre os direitos do usuário de serviços públicos de saúde mental, no campo econômico a recessão e a hiperinflação levam à crise do modelo previdenciário (Jorge, 1997) e à dificuldade de manter os altos custos estatais com manicômios particulares, favorecendo a reforma psiquiátrica (Andreoli, Almeida Filho, Martins, Mateus \& Mari, 2007). Nesse cenário, dois movimentos ligados à saúde se destacaram: o movimento sanitário, que buscou estabelecer a saúde como direito de toda a população, criando um sistema amplo e participativo, e o movimento antimanicomial, que questionou o paradigma do modelo clássico da psiquiatria. Ligados a instituições universitárias como o Centro Brasileiro de Estudos em Saúde (CEBES), a Associação Brasileira de Saúde Coletiva (ABRASCO) e o Movimento de Renovação Médica (REME), às Comunidades Eclesiais de Base e a outras instâncias redemocratizantes, ambos os movimentos tinham origens vinculadas e viram sua relevância crescer para além do campo da saúde, alçando a cena política geral do período.

O Sistema Único de Saúde (SUS) nasce então da reinvindicação popular por um modelo de assistência baseado na garantia de direitos, promoção da cidadania e perspectiva de integração das diversas dimensões de saúde, numa conjuntura nacional de fortificação dos direitos sociais. O movimento sanitário propõe universalização da saúde, ênfase na atenção básica e na medicina comunitária e controle popular da gestão, que se refletem na definição legal dos princípios de universalidade, integralidade, equidade, descentralização, regionalização, hierarquização e participação popular do SUS. Com a abertura política do período, o movimento sanitário inicia uma estratégia de ocupação dos cargos do Estado para efetivar o estabelecimento de um sistema universal de saúde. A princípio crítico quanto à relação entre saúde e sociedade, com questionamentos sobre a cientificidade do saber médico, a neutralidade das ciências, a validade das práticas de saúde não oficiais, etc., (Amarante, 2016), o movimento sanitário paulatinamente volta-se a sistematizar as ações de saúde, com maior ênfase na administração do sistema. Simultaneamente, no plano internacional, a expansão das políticas neoliberais a partir da década de 1980 leva a uma desarticulação das forças promotoras de uma visão de saúde voltada ao contexto social, pressionando pela diminuição das ações dos Estados voltadas aos direitos de cidadania, tendendo a tornar filantropia o que era considerado o direito social (Heimann, 2005). Tal conjuntura contribuirá para as dificuldades de ampliação do investimento público em saúde e consequente fortalecimento do SUS, refletindo-se sobre os problemas de abrangência do atendimento e sobre a escolha por serviços institucionalizados em detrimento de práticas individualizadas e territoriais, temas discutidos adiante.

A princípio denominado Movimento dos Trabalhadores de Saúde Mental (MTSM), o Movimento Antimanicomial tem como marco a crise na Divisão Nacional de Saúde Mental (DINSAM), que adquiriu projeção nacional, com denúncias e reivindicações que incluíam problemas como corrupção, violência, tortura, negligência, ausência de recursos, etc. A princípio com um caráter corporativista, reivindicando melhores condições de trabalho aos profissionais da área, o movimento progressivamente direcionou-se para a reformulação profunda dos paradigmas sobre a loucura e sua assistência, em que a violência das instituições psiquiátricas se relaciona de modo mais amplo com a violência do Estado militar contra os cidadãos. Diversos autores importantes visitaram o Brasil como Foucault, Guattari e Basaglia, influenciando o processo de reforma psiquiátrica brasileira, e diversos núcleos do movimento antimanicomial foram formados. Cabe observar que o próprio movimento antimanicomial é grandemente heterogêneo, não havendo consenso nem sobre o direcionamento da Reforma Psiquiátrica, nem sobre a noção de loucura ou o processo de reinserção social. Se por um lado essa diversidade enriquece as possibilidades de pensar o processo terapêutico, enfraquece politicamente a implementação de ações.

Do início a meados da década de 1980, surge o plano de reorientação da Assistência psiquiátrica, bem como diversos modelos de gestão compartilhada e a constituição dos Sistemas Unificados e Descentralizados de Saúde (SUDS), embrião do Sistema Único de Saúde (SUS). Inserido no Estado, o movimento sanitário realiza a $8^{\text {a }}$ Conferência Na- 
cional de Saúde, que pela primeira vez conta não apenas com técnicos e burocratas, mas com a sociedade civil, e torna a expressão Reforma Sanitária "lema nacional" (Amarante, 2016, p.92). Integrantes do MTSM também realizam conferências regionais e a $1^{\text {a }}$ Conferência Nacional de Saúde Mental (CNSM). O evento é marcado pela tensão: a DINSAM e a Associação Brasileira de Psiquiatria (ABP) buscam restringir a participação da população e a implantação de novas formas de organização da assistência, enquanto as articulações do MTSM pressionam por maior voz popular e mudanças estruturais, enfrentando resistências que Basaglia (2010) chegou a denominar de "culto do pessimismo".

Assim, a estratégia sanitarista assumia a direção de realizar pequenas modificações sem uma mudança estrutural, que atingisse o âmago da questão: o paradigma psiquiátrico pautado na relação entre ajustamento/opressão social e saber médico/ especializado. Após a $1^{\mathrm{a}} \mathrm{CNSM}$, inicia-se o período da "desconstrução/invenção" (Amarante, 2016, p. 93). No $2^{\circ}$ Congresso Nacional dos Trabalhadores de Saúde Mental, institui-se o lema "por uma sociedade sem manicômios", o Dia Nacional da Luta Antimanicomial e a intervenção na Casa de Saúde Anchieta e a posterior criação do Núcleo de Atenção Psicossocial (NAPS), serviço substitutivo que visa oferecer atendimento diário a usuários com sofrimento existencial que precisem de tratamento, e elabora-se o projeto de lei 3.657/89, embrião da lei 10.216/2001 (Lei Paulo Delgado), que formaliza a Reforma Psiquiátrica (Brasil, 2004).

Em 1992, o Brasil assina a Declaração de Caracas, pactuando com a reestruturação da assistência em saúde mental para assegurar direitos dos usuários (Hirdes, 2009) e regulamenta os Centros de Assistência Psicossocial pela portaria 224/92 (Brasil, 2004). Assim, embora na década de 1990 diversos pontos da reforma estivessem já em expansão, assiste-se à contradição entre a diretriz prevista no processo e sua efetivação. A pressão política do setor privado atrasou a aprovação da lei e levou a alterações de dispositivos significativos do texto, como a previsão de extinção progressiva dos hospitais psiquiátricos privados (Pinto \& Ferreira, 2010; Amarante, 2016). A demora em oficializar a reforma levou à criação de portarias pelo ministério da saúde visando operar mudanças na estrutura de assistência. Elas determinavam: inserção de equipes multiprofissionais, espaços para recreação, terapias complementares na internação, parâmetros de adequação das acomodações, restrição do tempo de internação a 60 dias (Ribeiro, Martins, \& Oliveira, 2009), criação de NAPS e ambulatórios de saúde mental com assistência voltada à reinserção social (Brasil, 2004). Todavia, as tentativas de implementação da reforma pelo executivo também encontravam dificuldades, como demonstra o Programa de Apoio à Desospitalização (PAD), de 1992, que pretendia utilizar os recursos economizados com a desativação de leitos hospitalares para o retorno de pacientes longamente internados às famílias de origem, repassando um salário mínimo e meio a elas, porém nunca foi efetivamente concretizado (Andreoli et al., 2007).
Entre o final da década de 1980 e meados da década de 1990, o movimento pela reforma psiquiátrica distancia-se do Movimento Sanitário, voltando-se para o viés desinstitucionalizante, adotando a estratégia de problematização da loucura junto à sociedade e preocupando-se não apenas com a sistematização dos serviços, mas com a possibilidade de redirecionar o ato de saúde na própria relação entre profissional e usuário. As tensões entre movimento sanitário e movimento antimanicomial são paradigmáticas de algumas questões que envolvem o campo da saúde mental em sua relação com o SUS. Embora possamos tomar esse campo como relativo à saúde, sua reorientação em direção à reinserção social exige a crítica aos paradigmas sedimentados pela medicina tradicional. Inicialmente, reconhece-se que a relação entre sintoma e substrato orgânico, bem como a fragmentação do corpo, presente no racionalismo médico, foi o eixo dos processos de exclusão social intermediados pela psiquiatria. A possibilidade de uma nova relação com a loucura implica a consideração dos "muitos corpos" (Basaglia, 2010) pelos quais somos formados: dimensões psicológicas, sociais, materiais, culturais, biológicas que não podem ser considerados elementos separados, mas compõem a totalidade da existência.

Nesse sentido, substitui-se o termo "doença mental" pelo termo "saúde mental", visando evitar o aprisionamento simbólico do indivíduo na condição de doente e a conotação de disfunção biológica presente na noção de doença, bem como enfatizar a promoção de melhores condições de saúde. Porém, ambas as expressões, "doença mental" e "saúde mental", precisam ser problematizadas, possuindo dois complicadores: mantêm o binômio saúde-doença, que tende a biologizar a loucura buscando causas orgânicas nunca claramente identificadas, e promovem a separação entre corpo e mente, como se o surto dissesse respeito apenas à "mente", seja ela compreendida como consciência ou mera atividade cerebral. Tais termos tendem a desconsiderar o fenômeno multidimensional implicado na loucura, excluindo elementos sociais e mesmo psicológicos.

A intersecção entre atenção ao sofrimento grave e sistemas e paradigmas da saúde em geral gera diversos conflitos. Embora o movimento de questionamento dos paradigmas da psiquiatria clássica tenha produzido diversas experiências substitutivas de cuidado, é a mesma catalogação de sintomas produzida pela psiquiatria clássica que permanece no Código Internacional de Doenças (CID) e no Diagnostic and Statiscal Manual of Mental Desorders (DSM). No CID, o grupo das esquizofrenias obedece, em grande parte, a classificação de Kraepelin, mesmo suas neurohipóteses não tendo sido comprovadas, mas estimadas a partir da quantificação sintomatológica (Foucault, 2000, Elkis, 2000).

Assim, a reforma psiquiátrica e os serviços substitutivos trazem uma ambiguidade semântica: ora designam a simples tentativa de recuperação do potencial terapêutico da psiquiatria clássica, ora denotam a intenção de reformulação profunda na compreensão das situações de crise existencial grave e do lugar social ocupado por seus personagens. 
Vários serviços substitutivos brasileiros surgiram inspirados em processos de reforma psiquiátrica no âmbito internacional, tais como experiências de análise institucional, comunidade terapêutica no modelo de Maxwell Jones, residências terapêuticas, programas de geração de renda, centros de atendimento comunitário e de convivência inspirados na Psiquiatria Democrática italiana, programas de ação territorial baseados na Psiquiatria Comunitária e na Psiquiatria de Setor, experiências de acompanhamento terapêutico baseadas na proposta argentina. Outras propostas surgem a partir de demandas brasileiras, embora sob influxo epistemológico de correntes internacionais. Tais experiências convivem no atual cenário de cuidado em saúde mental, no qual encontramos desde espaços asilares clássicos, de cunho manicomial, até experiências que articulam promoção da saúde e promoção da cidadania, enfatizando a crise como restrição do compartilhamento de experiências.

A Reforma psiquiátrica brasileira conhece maior avanço após a promulgação da lei 10.216/2001 (Brasil, 2004): entre 2002 e 2012, houve queda sistemática no número de leitos psiquiátricos (de 51.393 para 29.958) e no percentual de gastos com a rede hospitalar $(75,24 \%$ para $28,91 \%)$, acompanhados de aumento do número de Centros de Atenção Psicossocial (CAPS) (de 424 para 1981), aumento de gastos com serviços abertos (de $24,75 \%$ para $71,09 \%$ ), aumento de $68 \%$ no investimento em CAPS (de 460 milhões para 776 milhões) e aumento dos recursos destinados à saúde mental (de 619 milhões para 1,8 bilhão). Assim, a avanços têm ocorrido, como a instalação de serviços substitutivos, a diminuição de leitos em hospitais psiquiátricos e a criação de leitos em hospitais gerais (Brasil, 2007). Além disso, em 2004 foi implantado o Programa Nacional de Avaliação dos Serviços de Saúde, para garantir qualidade mínima das instituições públicas e privadas que recebem verba pública. No geral, evolui-se de 13 Núcleos de Atendimento Psicossocial (NAPS) ou Centros de Atenção Psicossocial (CAPS) e 80 mil leitos psiquiátricos em 1989 para 820 CAPS e 45 mil leitos em 2011 (Lancetti, 2011).

A mudança no repasse dos recursos expressa solidamente mudanças no modelo de atendimento, passando a enfatizar inclusão social e promoção da autonomia. Nesse quadro se desenvolvem programas e serviços voltados à desinstitucionalização e à criação de estratégias substitutivas em saúde mental. Porém, estabelecer novos espaços não significa por si só reformular o modelo assistencial. Permanecem em parte as contradições entre as iniciativas políticas e sua efetivação já encontradas na década de 1990. A Lei 10.708/2003 institui o programa de volta para casa e a Portaria GM 106/2000 institui residências terapêuticas (Brasil, 2004), porém a ressocialização de pessoas institucionalizadas pouco avança: ao contrário da implementação dos CAPS, os dispositivos envolvidos não chegam a sistematizar uma rede nacional. Do mesmo modo, a lei 10.216/2001 prevê a criação de oficinas de trabalho protegido e unidades de preparação para a reinserção social, que não chegam a ser implantadas sistematicamente. A cobertura dos serviços instalados resta insuficiente, havendo ainda despreparo de profissionais, famílias e comunidades para o convívio com pessoas em situação de sofrimento grave (Brasil, 2004).

\section{Desospitalização, desinstitucionalização e desafios da reforma psiquiátrica}

Ao abordar o desmonte do hospital psiquiátrico de Santos, Lancetti afirma que "a clínica reabilitativa é imanente ao processo de desmontagem manicomial" (2011, p. 21), sendo necessário contemplar ações que vão além da centralização no modelo biomédico, priorizando tratamento, reabilitação psicossocial, clínica territorial e projetos terapêuticos individualizados (PTI) (Hirdes, 2009). No entanto, no Brasil a diminuição de leitos nos hospitais psiquiátricos não acompanhou a criação de vagas na rede substitutiva; além disso, o sistema possui fragilidades em termos de abrangência, acessibilidade e diversificação (Alverga \& Dimenstein, 2006). Por outro lado, dispositivos abertos, embora evitem alguns elementos cronificadores ligados às instituições totais, só permitem reabilitação psicossocial e extinção do preconceito mediante crítica da lógica organicista, resgatando a diferença entre desospitalizar e desinstitucionalizar. Longe de significar apenas alterações nos serviços, a desinstitucionalização requer o reposicionamento epistemológico da loucura, situando-a nas relações entre sujeito e mundo, a fim de "desconstruir/construir - o cotidiano das instituições" (Basaglia, 2001, p. 94). Reinventam-se os modos de olhar e lidar com as questões apresentadas pelos indivíduos, num "processo ético-estético, de reconhecimento de novas situações que produzem novos sujeitos, novos sujeitos de direito e novos direitos para os sujeitos" (Amarante, 2016, p. 1).

Nesse sentido, é fundamenta uma capacitação profissional focada na desconstrução da concepção fragmentada e biológica de doença mental e do modelo assistencial dela decorrente, que tome o sujeito enquanto constituído nas diversas relações, em seu âmbito familiar, social e cultural e inclua o cuidado em saúde mental em todas as esferas do SUS e da rede de apoio psicossocial. Cabe lembrar a crítica de Rotelli (1991): nos últimos vinte anos, muitos países ocidentais tentaram reformar seus sistemas psiquiátricos pela estratégia de construir serviços externos ao hospital psiquiátrico. Todavia, as mudanças alcançaram poucos resultados em termos de reabilitação, melhoria da assistência, e redução da população internada, na Inglaterra, na França, nos países Escandinavos e na Alemanha. No processo estadunidense, a desospitalização dos doentes mentais tinha como objetivo reduzir despesas estatais (Kantorski, 2001), não se comprometendo com a implementação de serviços substitutivos que permitissem avaliar comparativamente sua atuação. Para serem efetivas, assim, a discussão sobre a pluralidade de dimensões ligadas ao sofrimento e o próprio processo histórico de estigmatização da loucura deve transcender modelos preestabele- 
cidos não em termos apenas organizacionais, mas na perspectiva do cuidado, integrando o processo terapêutico. Tal transformação exige diálogos junto ao paciente quanto a critérios sobre a capacidade de autonomia dos pacientes e a necessidade de atendimento fora do setting tradicional (Lancetti, 2011), questionando a hierarquia pautada na relação médico-paciente e incluindo de projetos culturais, de geração de renda, etc.

No campo da saúde em geral, embora tenha possibilitado um planejamento racional do sistema, a hierarquização contribuiu para o enrijecimento e burocratização das redes (Campos, 2010), fragmentando o atendimento e dificultando o acesso. No campo da saúde mental, a hierarquização implica um agravante: ela contrapõe-se à lógica do CAPS, em que um serviço atua em diferentes níveis, possibilitando que o usuário em crise grave mantenha seus vínculos (Zambenedetti \& Silva 2008). Assim, obriga a classificar tipos de crises, coloca o hospital como gerenciador da crise grave, podendo agravá-la ao romper vínculos em razão da internação, e ainda leva à compreensão do hospital como tratamento mais complexo, quando a maior complexidade reside em manter o usuário em meio aberto. Há muitos impasses na interface entre saúde mental e atenção básica, como priorizar casos graves e ainda atuar em promoção de saúde, estabelecer atendimentos compartilhados e evitar práticas que levem à psiquiatrização e medicalização frente à grande demanda e tendência à padronização e autonomização dos serviços, entre outras (Brasil, 2011).

Um último aspecto a considerar é que a escolha governamental, via portaria do Ministério da Saúde (Amarante, 2003) dos CAPS como referência de atendimento, em detrimento de propostas como acompanhamento terapêutico, consultórios de rua ou Centros de Convivência e Cultura (CECCO), privilegiou a instituição como lócus do tratamento, aumentando percalços para desinstitucionalizar e riscos de manicomializar o atendimento, num processo que Amarante (2003) denominou de "capsização”. A partir de 2011, a portaria 3088/2011 institui a Rede de Atenção Psicossocial (RAPS) que reorienta o cuidado em diferentes níveis de assistência. $\mathrm{Na}$ Atenção Básica, propõe o atendimento a partir dos serviços na Unidade Básica em saúde, Equipes de Saúde da Família, Consultório na Rua, Serviços de Atenção Residencial de Caráter Transitório e seus serviços de apoio, Centros de Convivência e Cultura. Já em Atenção Secundária temos os Centros de Atenção Psicossocial (CAPS) em suas diferentes modalidades. Compõem a Atenção de Urgência e Emergência: Serviço de Atendimento Móvel de Urgência (SAMU), Sala de estabilização, Unidade de Pronto Atendimento (UPA), que funciona 24 horas, hospitais gerais com leitos. O tripé composto pelos Serviços de residenciais terapêuticos (SRT), pelo Programa de volta para Casa (PVC) e pelo Programa de Redução de Leitos Hospitalares de Longa Permanência articula a desinstitucionalização de pacientes longamente internados (Brasil, 2008). Finalmente, Iniciativas de Trabalho e Renda com empreendimentos solidários e cooperativas sociais são previstas na Portaria 1169/2005 (Brasil, 2010). Embora a portaria $3088 / 2011$ habilite todos os níveis de atenção do SUS a atuar em saúde mental, situa apenas o Consultório na Rua, a Atenção Residencial de Caráter Transitório e os Centros de Convivência como serviços voltados à saúde mental na atenção básica, sendo os dois primeiros mais direcionados à população residente na rua. Na atenção secundária, a portaria 3088/2011 (Brasil, 2010) institui apenas os CAPS como serviço especializado, omitindo outros dispositivos voltados à população em sofrimento existencial grave porém sem crise aguda, tais como hospitais dia, acompanhantes terapêuticos, serviços de readaptação laboral e dispositivos de atendimento comunitário intensivo. Assim, usuários que não se adaptem à proposta institucional, ao ambiente relacional ou aos serviços oferecidos no CAPS de sua região têm dificuldades de acolhimento nesse nível de atenção.

$\mathrm{Na}$ atual sistematização da Rede de Atenção Psicossocial, diversos dispositivos já consagrados em experiências de reforma psiquiátrica são pouco explorados nas diretrizes governamentais para a reforma psiquiátrica brasileira. O Acompanhamento Terapêutico, desenvolvido no próprio país, nem mesmo é citado pela portaria do 3088/2011 (Brasil, 2010) como recurso na construção da rede de apoio em saúde mental; o diálogo aberto, metodologia de prevenção à internação e psiquiatrização no contexto da primeira crise amplamente utilizado em diversos países da Europa, possui apenas experiências isoladas no contexto brasileiro, geralmente ligadas ao campo acadêmico (Kantorski, 2017). Ateliês de reabilitação para o trabalho e o recurso a famílias acolhedoras remuneradas pelo estado para receber pacientes com alguma autonomia, que compõem a rede de saúde mental francesa, não possuem correspondência sistematizada no Brasil. Na Itália, o trabalho é considerado eixo fundamental da reinserção social, sendo a rede formada não apenas por centros de tratamento específico, mas por cooperativas mistas de trabalho, diretriz que não possui a mesma ênfase político-epistemológica na reforma psiquiátrica brasileira. Assim como outros documentos oficiais voltados à saúde mental, a portaria 3088/2011 enfatiza diretrizes como "diversificação das estratégias de cuidado” (art. 2, VI) e "desenvolvimento de atividades no território, que favoreça a inclusão social com vistas à promoção de autonomia e ao exercício da cidadania” (art. 2, VII), porém pouco explora dispositivos essenciais para tais diretrizes, promotores de ressocialização mista, que integram pessoas não usuárias de serviços de saúde mental no percurso terapêutico do paciente e criam estratégias de autonomia financeira e social necessárias para a desinstitucionalização efetiva. Dispositivos baseados em experiências exitosas internacionalmente, tais como os supracitados, foram incluídos em documentos elaborados durante o processo de reforma psiquiátrica, mas acabaram negligenciados devido à influência política de representantes contrários à reforma e nunca foram sistematizados e oferecidos de maneira abrangente e contínua na RAPs (Brasil, 2010). 
Elementos subjacentes às tensões da reforma, como a consideração aos fatores socioeconômicos envolvidos na situação de crise e o investimento estatal na garantia de direitos possuem grande influência na organização dos dispositivos da rede, havendo experiências em que a lógica manicomial subsiste, apesar da mudança de serviços, devido à estrutura ofertada. Por exemplo, embora o Ministério da Saúde tenha deliberado um CAPS para cada 150/200 mil habitantes, há regiões com um CAPS para uma população muito maior, dificultando a efetividade da rede substitutiva (Macedo, Abreu, Fontelle, \& Dimenstein, 2017). Ao atender demandas muito superiores à capacidade dos serviços, compromete-se a individualização da assistência no Projeto Terapêutico Singular e torna-se inviável o que Spohr e Schneider (2009) denominam atenção integral nas dimensões de vida do sujeito. Nesse contexto, assiste-se a uma aliança entre o desinvestimento do Estado e as concepções de saúde que trabalham na ótica de distanciamento do sujeito (Puchivailo et al., 2013) e biologização da loucura.

No quadro ora delineado, a reforma psiquiátrica brasileira enfrenta uma questão estrutural: a luta pela extensão da assistência a toda a população e pela implementação de serviços para além do tratamento medicamentoso já demanda grande mobilização para tornar-se efetiva, relegando frequentemente a segundo plano a importante discussão sobre o olhar epistemológico sobre a loucura. Embora isso seja inteligível como decorrente da ausência de condições adequadas de assistência e cobertura, é um grande risco, pois ofusca um dos eixos mais importantes para garantir a promoção efetiva de autonomia e inserção social nos serviços prestados. Essa questão pode auxiliar a compreender porque, embora muito influente, a contribuição fenomenológica na reforma psiquiátrica ainda seja pouco conhecida no Brasil. Por outro lado, é fator importante para compreender a ambiguidade instalada nos serviços abertos, nos quais as tentativas de reformulação do olhar sobre a loucura e de reinserção social convivem com práticas e discursos manicomiais, tais como a ênfase na medicação e no diagnóstico e a manutenção da concepção do usuário de serviços de saúde mental como "um sujeito que não sabe de si, sem liberdade nem responsabilidade sobre si” (Puchivailo et al., 2013, p. 232). Nesse sentido, serão discutidos a seguir dois dispositivos paradigmáticos: as Comunidades Terapêuticas e os CAPS. A escolha de tais dispositivos justifica-se pela importância que assumiram na rede substitutiva brasileira e por sua vinculação histórica aos debates epistemológicos em torno da loucura e das relações de poder na psiquiatria clássica. Os CAPS tornaram-se o eixo organizador da assistência em saúde mental no Brasil. Já as comunidades terapêuticas tornaram-se o principal dispositivo das organizações da sociedade civil e, em muitas regiões, consistem no principal espaço de institucionalização de usuários de álcool e drogas, senão no único.

Embora possamos encontrar diferenças na assistência ao uso de álcool e drogas frente a outras demandas de saúde mental, considera-se aqui o po- sicionamento de Basaglia (1980), para quem todos os fenômenos nesse campo requerem um olhar que privilegia a relação entre sujeito e mundo, partilhando a mesma crítica epistemológica à noção de doença mental, que fragmenta a existência na sintomatologia Nesse sentido, o uso de álcool e drogas não é considerado uma experiência à parte no contexto do sofrimento existencial grave, mas uma de suas expressões. Isso não significa desconsiderar aspectos históricos e políticos singulares dos sujeitos e situações, mas compreendê-los na relação eu-mundo. Diante de um mundo em que o consumo e a adicção são elementos cotidianos, pode emergir a vivência do abuso de substâncias psicoativas, assim como para Deleuze \& Guattari (2010) a fragmentação social das experiências liga-se à vivência esquizofrênica.

O processo de disseminação de comunidades terapêuticas no Brasil pode ser situado na própria tensão entre concepções disciplinares e promotoras de autonomia. Originalmente, as experiências de comunidade terapêutica baseiam-se na concepção de autogestão, participação e responsabilidade coletiva, compreendendo o atendimento enquanto criação de novos modos de relação com o outro e apropriação do espaço social, apoiado sobre os "pressupostos que tendem a desconstruir o princípio da autoridade na tentativa de programar uma condição comunitariamente terapêutica” (Basaglia, 2001, p. 117). No entanto, atuando principalmente no interior do espaço asilar, mesmo quando propõem modos democratizados de interação e a desconstrução das relações de violência, as comunidades terapêuticas tendem a criar um espaço paralelo e desarticulado do contexto externo de vida dos internos, constituindo-se como modelo idealizado de vida em grupo, à medida que separam o paciente do seu mundo social (Serrano, 1986).

É no contexto do risco disciplinar que a apropriação das comunidades terapêuticas por instituições de forte tradição religiosa pode reproduzir a segregação social ao associar o uso de drogas ao descrédito moral e à ideia de pecado. As primeiras comunidades terapêuticas religiosas fundam-se nos Estados Unidos na década de 1930. Da primeira experiência de amplo atendimento realizada pelo grupo de Oxford, voltado a restaurar os princípios da vida comunitária e caritativa cristã, originam-se experiências focalizadas na adicção: a Irmandade Alcoólicos Anônimos e o programa da Synanon, que sistematizou um modelo posteriormente difundido em diversos países (Fracasso, 2008). Essa diretriz religiosa é a mais difundida no Brasil: em pesquisa na base de dados SCieLO em novembro/2017, foram encontrados 57 artigos sobre comunidades terapêuticas. À exceção de um artigo histórico, todas as comunidades terapêuticas eram voltadas ao tratamento de álcool e drogas e possuíam caráter religioso.

Embora deva-se reconhecer a ampla importância social dessas iniciativas, em geral todas pressupõem o uso de substâncias psicoativas como doença incurável, embora controlável, e a aceitação de uma figura divina como elemento constituinte do processo de recuperação, assemelhando-se à proposta de Maxwell Jones apenas pelo aspecto de autogestão de 
algumas experiências pontuais. Em meio à tradição social autoritária brasileira, cujas experiências no âmbito da saúde mental foram frequentemente excludentes e repressoras (Antunes, 2014). O modelo de autogestão, proposto até mesmo nas comunidades terapêuticas religiosas originais, foi distorcido pela larga inserção de práticas manicomiais. A proposta de Comunidade Terapêutica de responsabilidade coletiva exige refletir constantemente sobre as relações entre os participantes. A concepção hierárquica do tratamento e dos saberes permanece atuante numa sociedade em que as desigualdades se encontram no cotidiano. Nesse quadro, a equipe responsável muitas vezes determina as atividades, regula interações com o meio externo, o uso de objetos do cotidiano e até mesmo as práticas relacionadas às crenças religiosas ou ideológicas dos internos. Desinvestindo num ambiente gerador de autonomia e do sujeito e contradizendo os propósitos iniciais das comunidades terapêuticas, tais práticas podem levar à "a desqualificação do interno como sujeito responsável, portanto, como um sujeito de direitos" (Conselho Federal de Psicologia, 2011, p. 193).

Assim, muitas instituições que recebem a denominação de comunidades terapêuticas estruturam relações autoritárias com os internos e portam-se como "mini-hospícios", não rompendo com a demarcação de espaço para a sanidade e loucura (Conselho Federal de Psicologia, 2011). Estes modelos de atendimentos comunitários criam dificuldades nos processos de reinserção social: não havendo um processo de construção da autonomia, os indivíduos podem apresentar dificuldades em retomar o cotidiano ao sair da instituição.

O CAPS é um serviço ambulatorial especializado em saúde mental, que visa o tratamento à pessoa em sofrimento existencial em suas diferentes manifestações. Em sua concepção teórica, preconiza o cuidado do indivíduo no território que ele ocupa, respeitando sua subjetividade, a concretude de sua vida com seus problemas, seu trabalho, relações com a família e a comunidade, seus projetos e anseios (Costa-Rosa, 2000). Sob tal prisma, a saúde não é compreendida a partir de normativas externas - princípios biomédicos, convenções governamentais ou supre governamentais - mas como construção dialogada com os sujeitos a partir do que lhes faz sentido em sua perspectiva de cuidado e sociabilidade. É nesse contexto que o território emerge como uma força viva de relações dinâmicas - concretas e imaginárias - estabelecidas pelo indivíduo tanto com outros indivíduos como com dispositivos de saúde, educação e cultura (Amarante, 2016). Assim, a perspectiva inicial de atendimento no CAPs se faz na construção de um percurso iniciado num tratamento mais intensivo e que caminha para referências da atenção básica conforme os laços, o apoio psicossocial e as práticas de cuidado vão se construindo no território.

No entanto, ainda hoje vemos alguns CAPS que atuam em uma lógica que não conseguiu romper com práticas tutelares. Diversos problemas traduzem a multiplicidade de meios pelos quais as brechas e interrupções no processo de reforma psiquiá- trica aliados aos interesses do mercado no campo da saúde mental reintroduzem discursos e práticas manicomiais no cotidiano da assistência à saúde. A massificação dos atendimentos, dificultando a elaboração desses projetos e uma maior atenção à crise dos sujeitos acompanhada em seu território, ocorre em resposta ao avanço do modelo neoliberal de produtividade por número de atendimentos na saúde. A centralidade na medicação psiquiátrica, sob influência do processo de medicalização da sociedade e carregando interesses tanto da indústria farmacêutica quanto de desinvestimento do Estado na melhoria de condições de vida da população, coopera para a reprodução de um olhar focado na ideia de doença mental, que destitui a autonomia e muitas vezes gera dúvidas, entre a equipe, sobre uma atuação voltada ao cuidado ou à tutela e à disciplina.

Há ainda dificuldades de diferentes ordens para encaminhar o usuário para outros espaços, o que exige o efetivo funcionamento da RAPS. Primeiramente, a privatização dos aparelhos de saúde mental via organizações sociais que prestam serviços ao Estado, gera uma fragmentação no direcionamento das políticas públicas. A centralidade dos CAPS na rede, anteriormente discutida, relega a segundo plano o investimento em importantes dispositivos de cuidado no território, abrangendo educação, cultura, capacitação e facilitação do acesso para o trabalho, esporte e lazer, etc, não havendo vagas suficientes. Além disso, nem sempre há espaços estruturados na rotina de comunicação entre os CAPS e outros dispositivos da rede, o que facilitaria a criação de cuidado no território acompanhada pelo CAPS conforme uma lógica de corresponsabilidade. Não havendo um fluxo de encaminhamento devido ao estancamento do atendimento no próprio CAPS, o número de pacientes tende a aumentar, intensificando os processos de massificação e dificultando o cuidado singular.

A longa permanência no CAPs, cronifica as próprias relações terapêuticas, podendo abrir espaço para uma repetitividade das práticas oferecidas que leva à perda de seu sentido e sua potencialidade para promoção da autonomia, reproduzindo apenas o lugar social de "doente" ocupado por usuários e o lugar de saber ocupado por técnicos. É no contexto da cronificação que assistimos ainda outro fenômeno: as constantes reinternações de pacientes em hospitais. Avanços de discursos como internação compulsória e medicalização, que conferem novas roupagens ao pensamento manicomial e aumento das reinternações psiquiátricas (Bezerra \& Dimenstein, 2011) frente à escassez de propostas de cuidado efetivo no território. A possibilidade de institucionalização torna menos urgente a necessidade de uma crítica das práticas de saúde e das dificuldades de efetividade terapêutica do atendimento. É nesse sentido que Rotelli (1991) chama a atenção que a proibição da recuperação em hospital psiquiátrico italiana relaciona-se diretamente à crítica realizada ao saber, poder e operacionalidade da psiquiatria que historicamente legitimou a exclusão de milhões de cidadãos, geralmente oriundos de classes menos favorecidas. 


\section{Considerações finais}

O movimento da Reforma Psiquiátrica no Brasil teve avanços na desinstitucionalização, mas muito ainda precisa se efetivar, numa reavaliação constante das práticas vigentes no sentido de um cuidado à pessoa em sofrimento existencial que traga para uma efetiva possibilidade de autocuidado e no qual haja instrumentalização dos trabalhadores de saúde e saúde mental, políticas que assegurem direitos e uma contínua preocupação com a qualidade do cuidado. Atuar tendo como perspectiva a reinserção psicossocial significa promover ações que intentem repensar as relações entre os dispositivos institucionais, a equipe e os integrantes da comunidade.

As dificuldades encontradas em se efetivar propostas de reinserção social e autonomia remetem à própria dificuldade de se construir relações pautadas no diálogo e na responsabilização coletiva. Numa sociedade que cria classificações e hierarquias para as experiências e os pontos de vista, prolifera a instituição de preconceitos e a construção de relações de dominação que subjugam o outro, reencontrada em instituições de saúde mental na argumentação pelo estabelecimento de hierarquias, nas proibições, nas práticas tutelares, no controle e na repetição das atividades cotidianas dos internos, etc.

A efetivação da reforma psiquiátrica se dá pela construção de contradiscursos e perspectivas questionadoras das hierarquias socialmente sedimentadas em relação a um padrão social de conduta, no qual aqueles que não correspondem a um ideal racional, produtivo, heteronormativo, disciplinar e adaptativo são considerados socialmente desviantes. Nesse sentido, quando a reforma psiquiátrica deixa de se politizar e de problematizar a própria concepção epistemológica da loucura, corre o risco de se manicomializar. A desconstrução de um modelo único de compreensão das singularidades necessita do questionamento das perspectivas socioculturais que consideram as questões do sofrimento psíquico em termos de doença ou marginalidade. É nesse sentido que a perspectiva fenomenológica vem a contribuir, no questionamento de interpretações sedimentadas sobre a existência e num posicionamento epistemológico que parte dos fenômenos e da relação com o outro.

Tal desconstrução necessita ainda de intervenções institucionais que permitam a reelaboração de práticas e perspectivas em direção à promoção da cidadania e da dignidade dos sujeitos, criando espaços que suscitem compreensões e sejam geradas transformações no modo como é entendida a práxis, além de novos sentidos para as vivências. Sem a articulação entre as propostas de problematização e reinvenção das relações humanas nos dispositivos substitutivos e a reconstrução das relações sociais no território, corre-se o risco de, paulatinamente, haver uma miscigenação das concepções manicomiais no próprio cotidiano dos serviços de saúde mental. A pesquisa de alternativas de discussão e compreensão do sofrimento humano e de práticas mais condizentes com um processo de reinserção social requer um questionamento das relações estabelecidas e das estruturas classificatórias da conduta que se direciona não apenas ao atendimento direto, mas também a uma problematização social e cultural dos processos de exclusão, em que a Rede não é apenas de serviços, mas implica toda rede de relações da sociedade, criando novas possibilidades de vida, cultura, afeto, experiência.

\section{Referências}

Alverga, A. R., \& Dimenstein, M. (2006). A reforma psiquiátrica e os desafios na desinstitucionalização da loucura. Interface - Comunic., Saúde, Educ., 10(20), 299-316. http://dx.doi.org/10.1590/S1414$\underline{32832006000200003}$

Amarante, P. (2003) (Org.). Saúde mental, políticas e instituições: programa de educação à distância. Vol. 1-10 Rio de Janeiro: Fiotec/Fiocruz.

Amarante, P. (2016). Loucos pela vida: a trajetória da reforma psiquiátrica no Brasil. Rio de Janeiro: Fiocruz.

Andreoli, S. B., Almeida-Filho, N., Martin, D., Mateus, M. D., \& Mari, J. J. (2007). Is psychiatric reform a strategy for reducing the mental health budget? The case of Brazil. Revista Brasileira de Psiquiatria, São Paulo, 29(1), p. 43-46. http://dx.doi.org/10.1590/ $\underline{\text { S1516-44462006005000032 }}$

Antunes, M. A. M. (2014). A Psicologia no Brasil: leitura histórica sobre sua constituição. São Paulo: Unimarco: EDUC.

Arbex, D. (2013). Holocausto Brasileiro. São Paulo: Geração Editorial.

Basaglia, F. (1980). Em busca das necessidades perdidas. In: M. Feliz (Org.), Encontros Com a Civilização Brasileira. Rio de Janeiro: Civilização Brasileira.

Basaglia, F. (2001). A instituição negada. Rio de Janeiro: Graal.

Basaglia, F. (2010). Escritos selecionados em saúde mental e reforma psiquiátrica. Organização: Paulo Amarante. (J. A. d'Á. Melo Trad.). Rio de Janeiro: Garamond.

Bezerra, C. G., \& Dimenstein, M. (2011). O fenômeno da reinternação: um desafio à Reforma Psiquiátrica. Mental, 9(16), 303-326.

Binswanger, L. (2009). Tres Formas de La Existencia Frustrada. Buenos Aires: Amorrortu.

Binswanger, L. (2013). Sonho e existência. Rio de Janeiro: Via Verita.

Breuer, J. \& Freud, S. (1895/1990). Estudos sobre a histeria. In: S. Freud. Edição Standard das Obras Cmpletas de Sigmund Freud. v. 2 (p. 15-297). Rio de Janeiro: Imago. 
Brasil (2004). Legislação em Saúde Mental 1990-2004. Brasília: Ministério da Saúde. Disponível em http:// bvsms.saude.gov.br/bvs/publicacoes/legislacao saude_mental_1990_2004_5ed.pdf

Brasil (2007). Saúde Mental no SUS: acesso ao tratamento e mudança do modelo de atenção. Relatório de Gestão 2003-2006. Brasília: Secretaria de Atenção à Saúde/DAPE/Ministério da Saúde. Disponível em http://bvsms.saude.gov.br/bvs/publicacoes/relatorio_gestao_saude_mental_2003-2006.pdf

Brasil (2008). Mostra Fotográfica Programa De Volta para Casa. Brasília: Ministério da Saúde. Disponível em: http://bvsms.saude.gov.br/bvs/publicacoes/mostra fotografica_programa_volta_casa_p1.pdf

Brasil (2010). Legislação em Saúde Mental - 2004 a 2010. Brasília: Ministério da Saúde. Disponível em http:// www.saude.pr.gov.br/arquivos/File/Legislacao_em saude_mental_2004_a_2010.pdf

Brasil (2011). Saúde Mental no SUS: as novas fronteiras da Reforma Psiquiátrica. Relatório de Gestão 2007/2010. Brasília: Ministério da Saúde. Disponível em: http://bvsms.saude.gov.br/bvs/publicacoes/ saude_mental_fronteiras_reforma_psiquiatrica.pdf

Campos, M. de. (2010). O grupo das esquizofrenias ou demência precoce: relatório apresentado ao III Congresso Brasileiro de Neurologia, Psiquiátrica e Medicina Legal. Rio de Janeiro. Julho de 1929. História, Ciências, Saúde-Manguinhos, 17(Suppl. 2), 709-732. http://dx.doi.org/10.1590/S0104$\underline{59702010000600030}$

Conselho Federal de Psicologia. (2011). Relatório da $4^{a}$ Inspeção Nacional de Direitos Humanos: locais de internação para usuários de drogas. Brasília: Conselho Federal de Psicologia.

Cooper, D. (2013). Psychiatry and Anti-Psychiatry. (1a reprint). New York: Ballantine.

Costa-Rosa, A. 2000. O modo psicossocial: um paradigma das práticas substitutivas ao modo asilar. In: Paulo Amarante (Org.). Ensaios: subjetividade, saúde mental, sociedade (p. 141-168). Rio de Janeiro: Fiocruz.

Deleuze, G. \& Guattari, F. (2010). O anti-édipo, o capitalismo e esquizofrenia. São Paulo: Ed. 34.

Deleuze, G. \& Guattari, F. (2015). Mil Platôs. São Paulo: Ed. 34.

Elkis, H. (2000). A evolução do conceito de esquizofrenia neste século. Revista Brasileira de Psiquiatria (São Paulo), 22 (Supl.1), 23-26. http://dx.doi.org/10.1590/ S1516-44462000000500009

Foucault, M. (2000). Doença mental e psicologia. Rio de Janeiro: Tempo Brasileiro.

Foucault, M. (2006). Microfísica do poder. São Paulo: Graal.
Foucault, M. (2014). História da loucura na Idade Clássica. São Paulo: Perspectiva.

Fracasso, L. (2008). Comunidade terapêutica: uma abordagem psicossocial. Encontro Interdisciplinar: Dependência Química, Saúde e Responsabilidade Social - Educando e Transformando Através da Educação Física. Recuperado em 14 fevereiro, 2017, de http://www.fef.unicamp.br/bibli/Encontrointerdisciplinar/Texto\%202\%20Laura.pdf

Goffman, E. (2001). Manicômios, prisões e conventos. São Paulo: Perspectiva.

Heimann LS. (2005). Desafios para a equidade em saúde na região metropolitana de São Paulo. In L.S.Heimann, L.C. Ibanhes \& R. Barboza (Orgs). O público e o privado na saúde (p. 169-243). São Paulo: Ed. Hucitec.

Hirdes, A. (2009). A reforma psiquiátrica no Brasil: uma (re)visão. Ciência \& Saúde Coletiva, 14(1), 297-305. https://dx.doi.org/10.1590/S1413$\underline{81232009000100036}$

Jaspers, K. (1913/2003). Psicopatologia geral. São Paulo: Atheneu.

Jones, M. (1972). Comunidade Terapêutica. Petrópolis: Vozes.1979.

Jorge, M. A. S. (1997). Engenho dentro de casa: sobre a construção de um serviço de atenção diária em saúde mental. Dissertação de Mestrado, Escola Nacional de Saúde Pública: Fundação Oswaldo Cruz, Rio de Janeiro.

Kantorski, L. P. (2001). A Reforma Psiquiátrica: um estudo parcial acerca da produção científica. Revista Eletrônica de Enfermagem (Goiânia), 3 (2). Disponível em: https://revistas.ufg.br/fen/article/view/721

Kantorski, L. P., \& Cardano, M. (2017). Diálogo Aberto: a experiência finlandesa e suas contribuições. Saúde em Debate, 41(112), 23-32. https://dx.doi. org/10.1590/0103-1104201711203

Laing, R. (1991). O eu dividido: estudo existencial da sanidade e da loucura. Petrópolis: Vozes.

Lancetti, A. (2011). Saúde e Loucura: Saúde Mental e Saúde da Família. São Paulo: Hucitec.

Macedo, J. P., Abreu, M. M. de, Fontenele, M. G., \& Dimenstein, M. (2017). A regionalização da saúde mental e os novos desafios da Reforma Psiquiátrica brasileira. Saúde e Sociedade, 26(1), 155-170. https://dx.doi.org/10.1590/s0104-12902017165827

Meirelles, M. (2016). Os bobos em Goiás: enigmas e silêncios. São Paulo: Biblioteca Virtual do Instituto Vox de Pesquisa em Psicanálise.

Messas, G. P. (2008). O espírito das leis e as leis do espírito: a evolução do pensamento legislativo brasileiro em saúde mental. História, Ciências e Saúde - Manguinhos, 15 (1): 65-98. http://dx.doi.org/10.1590/ $\underline{\text { S0104-59702008000100005 }}$ 
Passos, I. F. (2009). Reforma Psiquiátrica: as experiências francesa e italiana. Rio de Janeiro: Fiocruz.

Pessotti, I. (1994). A loucura e as épocas. São Paulo: Ed. 34.

Pessotti, I. (2006). Sobre a teoria da loucura no século XX. Temas em Psicologia, 14(2), 113-123.

Pinto, A. T. M., \& Ferreira, A. A. L. (2010). Problematizando a reforma psiquiátrica brasileira: a genealogia da reabilitação psicossocial. Psicologia em Estudo, Maringá, 15(1), p. 27-34. http://dx.doi.org/10.1590/ $\underline{\mathrm{S} 1413-73722010000100004}$

Puchivailo, M. C., Silva, G. B. da, \& Holanda, A. F. (2013). A reforma na saúde mental no brasil e suas vinculações com o pensamento fenomenológico. Revista da Abordagem Gestáltica, 19(2), 230-239.

Ribeiro, M. B. S., Martins, S. T. F., \& Oliveira, L. R. (2009). Familiares de usuários vivenciando a transformação do modelo assistencial psiquiátrico. Estudos de Psicologia, 14(2), p. 133-140.

Serrano, A. I. (1986). O que é psiquiatria alternativa? São Paulo: Ed. Brasiliense.

Tatossian, A. e Moreira, V. (2012) Clínica do Lebenswelt: psicoterapia e psicopatologia fenomenológica. São Paulo: Escuta. Coleção Pathos.

Spohr, B., \& Schneider, D. R. (2009). Bases epistemológicas da antipsiquiatria: a influência do Existencialismo de Sartre. Revista da Abordagem Gestáltica, 15(2), 115-125.

Vecchia, M. D. D., \& Martins, S. T. F. (2009). Desinstitucionalização dos cuidados a pessoas com transtornos mentais na atenção básica: aportes para a implementação de ações. Interface (Botucatu); 13(28):151-164. http://dx.doi.org/10.1590/S1414$\underline{32832009000100013}$

Waidman., M. A. P., \& Elsen, I. (2006). Os caminhos para cuidar da família no paradigma da desinstitucionalização: Da utopia à realidade. Ciência, Cuidado e Saúde, 5, 107-112.

Zambenedetti, G.; Silva, R. A. N. (2008). A noção de rede nas reformas sanitária e psiquiátrica no Brasil. Psicologia em revista, 14 (1), 131-150.
Marciana Gonçalves Farinha é professora da Universidade Federal de Uberlândia. Mestre em Psicologia e Doutorado em Enfermagem Psiquiátrica pela Universidade de São Paulo. Email: mgfarinha@hotmail.com

Tatiana Benevides Magalhães Braga é Graduada em Psicologia pela Universidade de São Paulo, Mestre e Doutora em Psicologia Escolar e do Desenvolvimento Humano pela Universidade de São Paulo. Professora Adjunta da Universidade Federal de Uberlândia, Membro da Sociedade de Psicologia de São Paulo e do Fórum contra a Medicalização da Educação e da Sociedade. Email: tatibmb@gmail.com

Recebido em 21.05.2017

Primeira Decisão Editorial em 25.07.2017

Aceito em 04.12.2017 